\title{
A Dual-band Microstrip Slotted Antenna for UHF and Microwave RFID Readers
}

\author{
Ahmed El Hamraoui ${ }^{\star 1}$, El Hassan Abdelmounim ${ }^{2}$, Jamal Zbitou ${ }^{3}$, Ahmed Errkik $^{4}$, \\ Hamid Bennis ${ }^{5}$, Mohamed Latrach ${ }^{6}$ \\ ${ }^{1,2}$ ASTI Laboratory, FSTS, Hassan 1st University, Settat, Morocco \\ ${ }_{3,4}$ LMEET, FSTS, Hassan 1st University, Settat, Morocco \\ ${ }^{5}$ TIM Research Team, EST of Meknes, Moulay Ismail University, Meknes, Morocco \\ ${ }^{6}$ Microwave Group, ESEO, Angers, France \\ *Corresponding author, e-mail: a.elhamraoui@uhp.ac.ma
}

\begin{abstract}
In this paper a new and simple dual-band microstrip slot antenna design combined with two inverted L-shaped slots integrated in the radiating patch is presented. This antenna is suitable for operating at $915 \mathrm{MHz}$ and $2.45 \mathrm{GHz}$ in order to cover the Radio Frequency Identification (RFID) frequencies bands. By optimizing the structure design, good performances in term of return loss radiation pattern and efficiency are achieved. The simulation results were obtained by using ADS and CST Microwave Studio electromagnetic solvers. The proposed antenna is mounted on an FR4 substrate with dielectric permittivity constant 4.4, thickness of $1.6 \mathrm{~mm}$ and loss tangent of 0.025 and a total area of $48 \times 47$ $\mathrm{mm}^{2}$. The design methodology used to achieve the dual-band antenna and both experimental, simulated results are presented.
\end{abstract}

Keywords: antenna, dual-frequency operation, microstrip fed, L-shaped slot, RFID (radio frequency identification), slot antenna

Copyright $\odot 2018$ Universitas Ahmad Dahlan. All rights reserved.

\section{Introduction}

In the last years Radiofrequency Identification (RFID) technology has been widely implemented in a variety of applications such logistics, supply chain management system and shop security [1]; hence RFID technology tends to replace the old techniques such barcode and smart cards [2]. Generally, an RFID system is based on two main components : a reader and a transponder (tag). The RFID reader transmits the RF power with an interrogating signal using the antenna to the tag and switch to the receiving mode in order to capture the backscattered signal from the tag, this signal contains the data stored in the microchip integrated in the tag. Figure 1 exemplify the block diagram of RFID system.

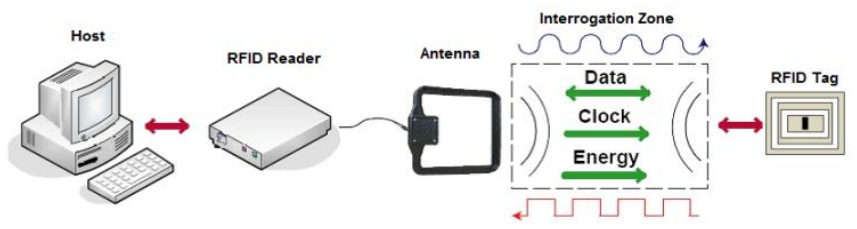

Figure 1. Block diagram of RFID system

Diverse frequency bands have been allocated for the RFID technology. The Lowfrequency (LF, 125-134 kHz) and high-frequency (HF, $13.56 \mathrm{MHz}$ ) which provide short reading ranges and low data rate. RFID systems operate at $860-960 \mathrm{MHz}$ for Ultra-high frequency band and at 2.4-5.8 GHz for microwave band offering good capabilities in term of high data rate and long reading range [3-4]. To meet this requirements, the antenna as one of the sensitive components in the RFID reader that affect the performance of whole RFID system [5-6] has been paid a great attention especially for applications involving RFID handheld reader. In order 
to provide small and compact wireless devices the requirements for small antenna capable of easily integration while providing good performances become an important criteria, hence microstrip patch antennas are considered a good choice for this kind of applications [7-9]. Several printed antennas were designed for dual band RFID applications [10-14], especially in UHF band (860-960) MHz and microwave band $2.45 \mathrm{GHz}$, enabling the use of a single antenna for different frequency bands. The tri-band fractal microstrip antenna proposed in [15] operates at $915 \mathrm{MHz}, 2.45 \mathrm{GHz}$ and $5.8 \mathrm{GHz}$ with dimension of $71.6 \times 94 \mathrm{~mm}^{2}$. The dual band printed dipole antenna presented in [16] resonates at $867 \mathrm{MHz}$ and $2.45 \mathrm{GHz}$ to cover the RFID and WSN applications, it has a dimension of $35 \times 76 \mathrm{~mm}^{2}$. The dipole antenna presented in [17] with a total size of $30 \times 59.5 \mathrm{~mm}^{2}$ is based on a modified Koch Fractal geometry in order to achieve the dual frequency operation. The main drawbacks of these antennas are principally their no compact structure and the complications in fabrication process.

In this work, a new design of a compact dual-band slot antenna is discused. The design consideration for the achievement of the rectangular slot antenna in the desired dual-band frequency bands permits to obtain a significant size reduction of $50 \%$ compared to a conventional patch antenna. The next sections present the details of the design considerations for achieving dual-band antenna along with both simulated and experimental results.

\section{Antenna Design}

The geometry of the proposed antenna is shown in Figure 2. The antenna is mounted on a low cost FR4_epoxy substrate with a relative permittivity of 4.4. The thickness of the substrate is $\mathrm{H}=1.6 \mathrm{~mm}$ and total area of $48 \times 47 \mathrm{~mm}^{2}$. The structure is excited using a microstrip feed line capable of increasing the bandwidth and gain. The design procedure of the initial geometry of the proposed antenna based on the basic rectangular patch as shown in Figure 2 is derived from the theoritical equations discussed in [18].

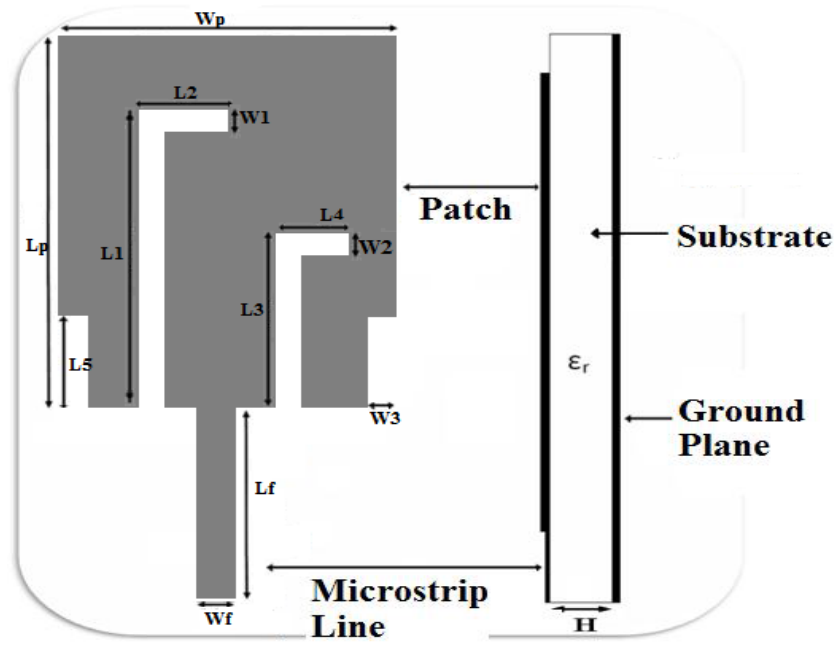

Figure 2. Geometry of the proposed antenna

The conception of the dual-band slotted antenna is based on the use of the multiple resonances introduced by the combination optimization of the antenna geometry and inverted Lshaped slot on the radiator patch. This technique extends the current lines to produce long path around the slit hence an additional resonances appear at the desired frequencies. The lengths of the inserted L-shaped slots can be expressed as a function of the guide wavelength $\left(\lambda_{\mathrm{g}}\right)$ that is given by the equation: 


$$
\lambda g=\frac{\lambda_{0}}{\sqrt{\varepsilon e f f}}
$$

where $\lambda_{0}=\frac{c}{f}$ is the wavelength in free space and $\varepsilon_{\text {eff }}$ is the effective dielectric permittivity calculated using (3). According to the previous equations, $\lambda_{\mathrm{g}}$ correspond to $110.15 \mathrm{~mm}$ at frequency $2.45 \mathrm{GH}$ and $296.5 \mathrm{~mm}$ at frequency $915 \mathrm{MHz}$.

The first slot length $L_{T 1}\left(L_{3}+L_{4}=21.5 \mathrm{~mm}\right)$ corresponds to about 0.24 wavelength at $\mathrm{fr}=2.45 \mathrm{Ghz}$ and the second slot length $\mathrm{L}_{\mathrm{T} 2}\left(\mathrm{~L}_{1}+\mathrm{L}_{2}=33.5 \mathrm{~mm}\right)$ corresponds to about 0.12 wavelength at $\mathrm{fr}=0.915 \mathrm{Ghz}$. The final parameters of the optimized structure are listed in the Table 1.

Table 1. Dimension of the Proposed Antenna (unit in $\mathrm{mm}$ )

\begin{tabular}{cc}
\hline Parameter & Value \\
\hline Lsub & 48 \\
Wsub & 47 \\
Lp & 27.5 \\
Wp & 37.26 \\
L1 & 25.5 \\
L2 & 8 \\
L3 & 14.5 \\
L4 & 7 \\
L5 & 9 \\
Lf & 18 \\
Wf & 1.5 \\
W1=W2 & 2 \\
W3 & 3 \\
\hline
\end{tabular}

\section{Simulation Results and Discussion}

The study of the performances of the proposed antenna was carried out by using CST simulation software, this simulation tool implement a numerical analyse methode based on the Finite Integration Technique [19]. In order to validate the simulation results obtained with CSTMW, a second study based on ADS software "Advanced Design System" with the claculation Method of Moment (MoM) [20] was conducted. The obtained simulated return loss is presented in Figure 3. According to this result, we can deduce that the results from the two solvers are in a good agreement with a small difference which is due to the different numerical methods used in these electromagnetic solvers.

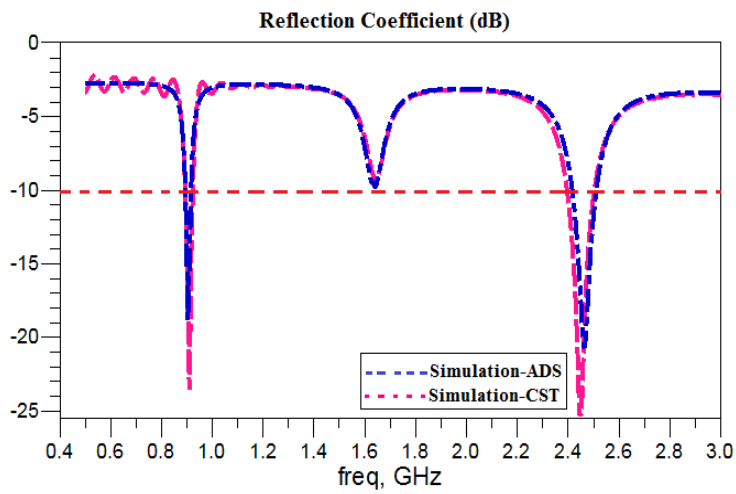

Figure 3. The simulated reflection coefficient for the proposed dual-band antenna obtained using CST and ADS

The frequency response of the designed dual band antenna is affected by different parameters. Figure 4 , illustrates the variation of the simulated reflection coefficient for different 
values of $L_{1}$. As can be seen from Figure 4 , the center resonance frequency of the first band decreases with the increase of $L_{1}$ and the first band remain constant. Figure 5 illustrates the simulated reflection coefficient curves with varied $L_{4}$. It is clear that when $L 4$ increases, the center frequency of the second band decreases whereas the first band knows a slight shift.

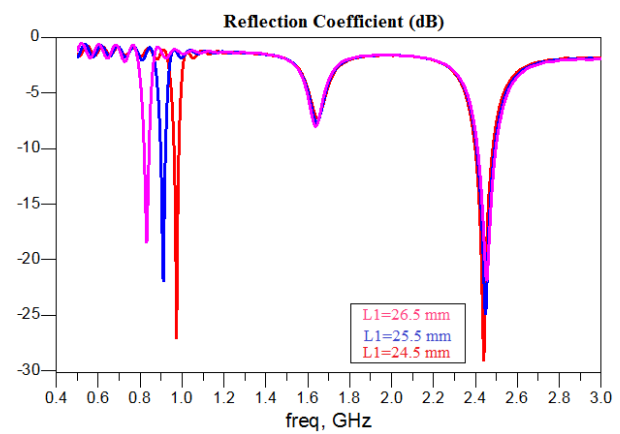

Figure 4. Curves of simulated reflection coefficient with varied $L_{1}$ while other parameters fixed

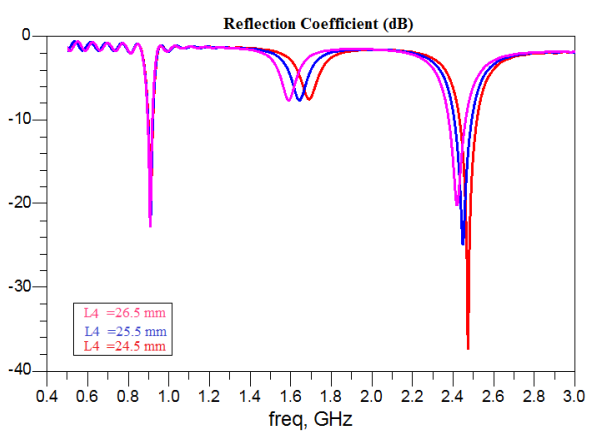

Figure 5. Curves of simulated reflection coefficient with varied $L_{4}$ while other parameters fixed

According to this analysis, the two desired frequency bands can be tuned independently by modifying the values of the lengths of the slots inserted in the patch, respectively. The current distributions of the proposed antenna for the two resonant frequency bands are illustrated in Figure 6. We can clearly notice that the surface current distributions at these two frequencies are not similar. When the first resonant frequency is at $0.915 \mathrm{GHz}$ as shown in Figure 6.a, most of the surface current is concentrated near the longest slot. As indicated in Figure 6.b, the surface current distribution becomes more condensed on the short slot of the rectangular patch and it is also concentrated along the feed line at $2.45 \mathrm{GHz}$.

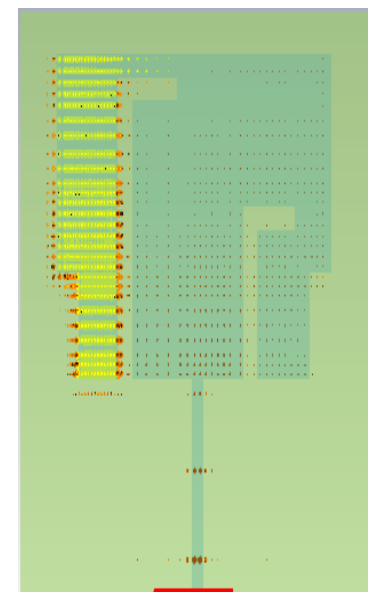

(a)

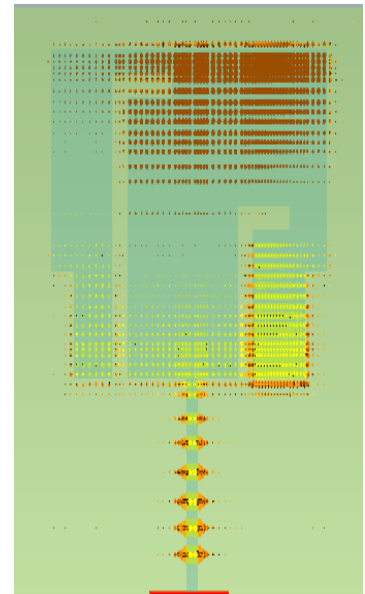

(b)

Figure 6. The antenna current distributions at $0.915 \mathrm{GHz}$ (a) and $2.45 \mathrm{GHz}$ (b)

The Figure 7 presents the antenna $2 \mathrm{D}$ radiation pattern in the plane $\mathrm{E}$, which is shown that the antenna is slightly directional in the low and high frequency bands, this result is explained by the effect of the ground plane acting as a reflector. 


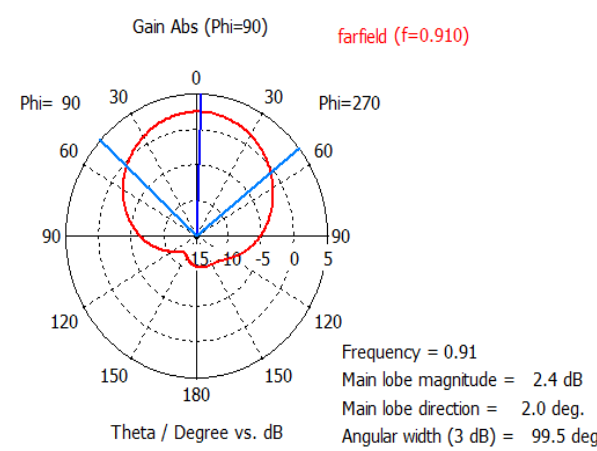

(a)

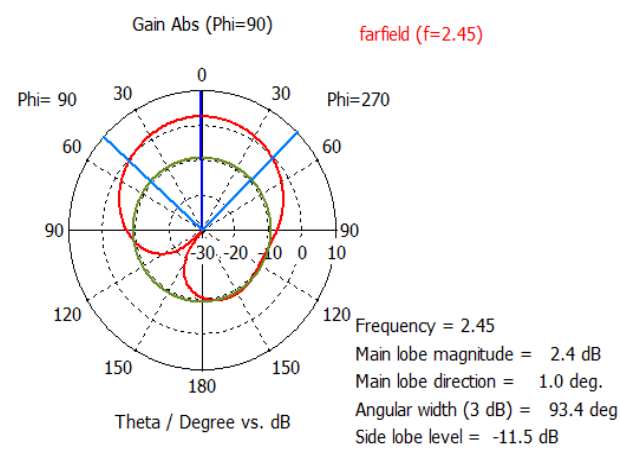

(b)

Figure 7. The antenna 2D radiation pattern in $\mathrm{E}-$ plane at $0.91 \mathrm{GHz}(\mathrm{a})$ and $2.45 \mathrm{GHz}$ (b)

The antenna 2D radiation pattern in the plane $\mathrm{H}$ is given by Figure 8, which is shown that the antenna is bidirectional in the high frequency $2.45 \mathrm{GHz}$. The calculation of the directivity is about $2.22 \mathrm{dBi}$ and $6.16 \mathrm{dBi}$ (Simulation gain) at $0.915 \mathrm{GHz}$ and $2.45 \mathrm{GHz}$ respectively.

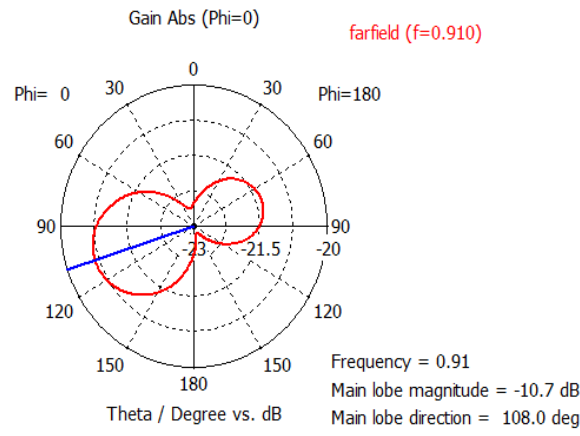

(a)

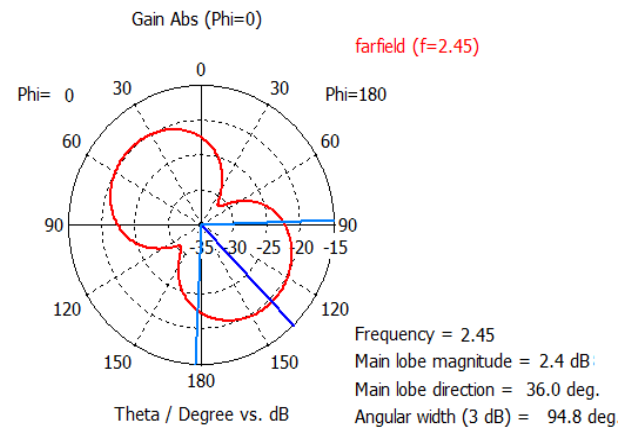

(b)

Figure 8. The antenna 2D radiation pattern in $\mathrm{H}$-plane at $0.91 \mathrm{GHz}(\mathrm{a})$ and $2.45 \mathrm{GHz}(\mathrm{b})$

\section{Achievement and Measurement}

In this section, the fabrication of the prototype of the investigated antenna was carried out using the LPKF machine, which permits to validate the optimized structure. The result of the measurement of return loss is obtained using Vectorial Network Analyzer (VNA) PNA-X from Agilent Technologies. Figure 9 gives the picture of the fabricated dual band antenna.

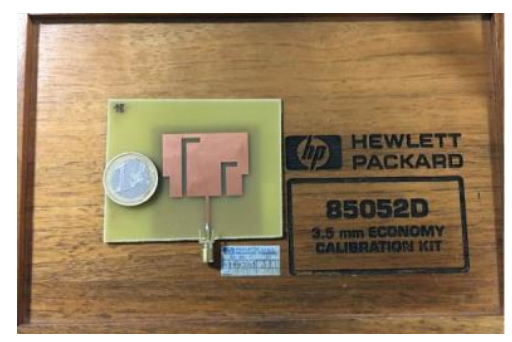

Figure 9. Photograph of the realized antenna 
The Figure 10 shows the kit of calibration of $3.5 \mathrm{~mm}$ used to take into consideration the losses in the different transitions, this kit is composed from Open, Short and Load components. The measured return loss for the achieved antenna obtained after the calibration is shown in the Figure 11 along with the simulations results on ADS and CST.

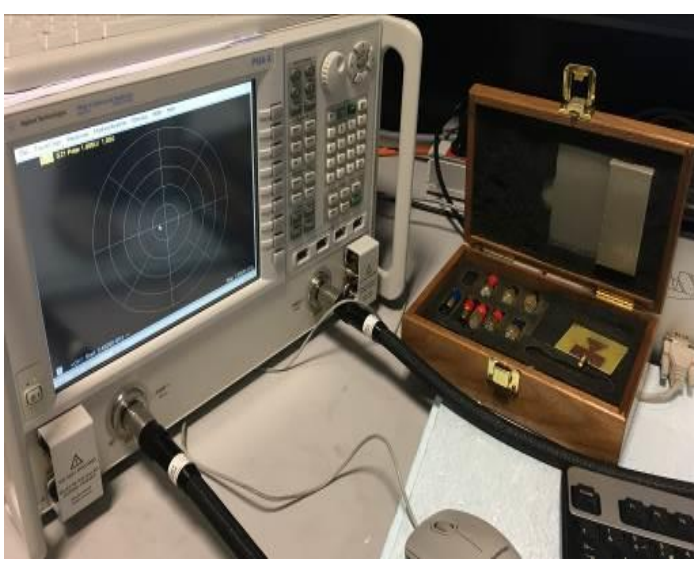

Figure 10. Calibration Kit $3.5 \mathrm{~mm}$

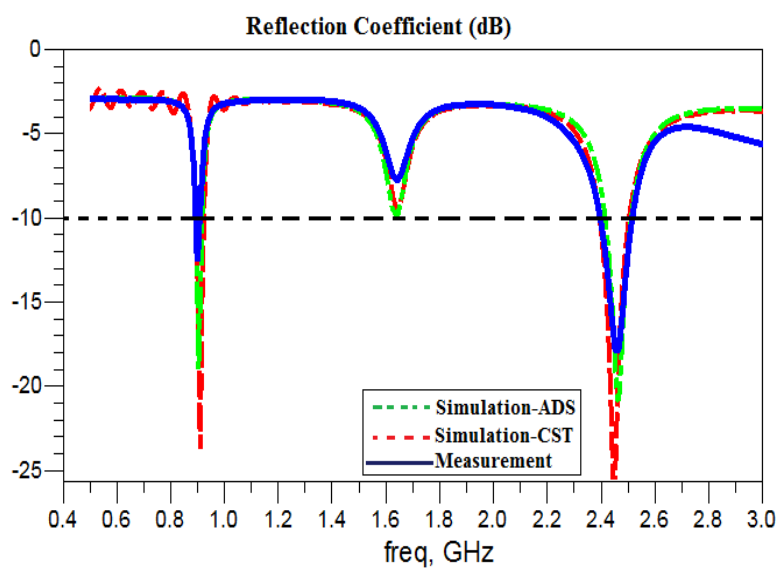

Figure 11. Measured reflection coefficient compared to that obtained in simulation

We notice that there is a good concordance between simulation and measurement results of the return loss. The slight difference noticed between the measured and simulated results is mainly due to the fabrication constraints such as the effect of soldering at SMA connector and variation of dielectric permittivity, dissipation factor at high frequencies.

From the measured reflection coefficient curve we deduce that the antenna exhibits a $10 \mathrm{~dB}$ return loss bandwidth of $100 \mathrm{MHz}(2.4-2.5 \mathrm{GHz})$ at $2.45 \mathrm{GHz}$ and an impedance bandwidth of $28 \mathrm{MHz}(0.900-0.928 \mathrm{GHz})$ at $0.915 \mathrm{GHz}$. The Figure 12 shows the antenna under test in anechoic chamber used for the measurement of the radiation patterns.

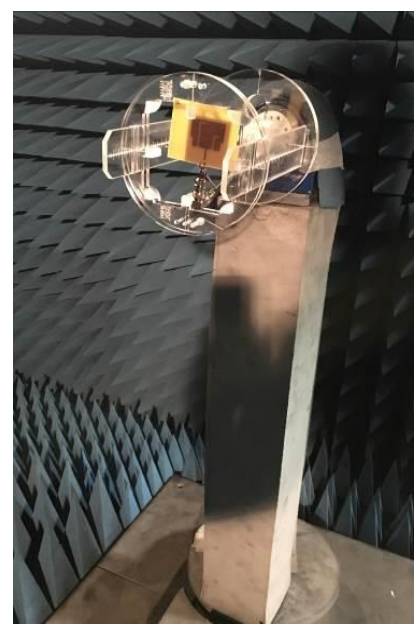

Figure 12. Anechoic chamber

The Figure 13 and 14 present the measured far-field radiation pattern characteristics of the proposed antennas in E-plane and $\mathrm{H}$-plane respectively at $0.915 \mathrm{GHz}$ and $2.45 \mathrm{GHz}$. The measured results shows that the antenna radiates omni-directionally in the $\mathrm{H}$-plane and nearly bidirectionally in the E-plane at the two operating frequency bands. 


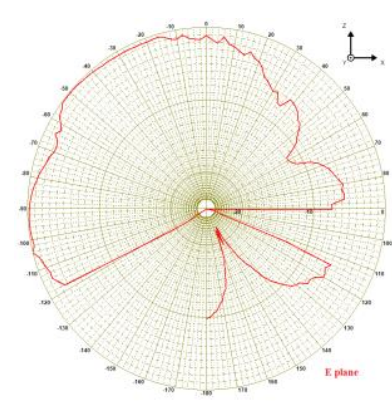

(a)

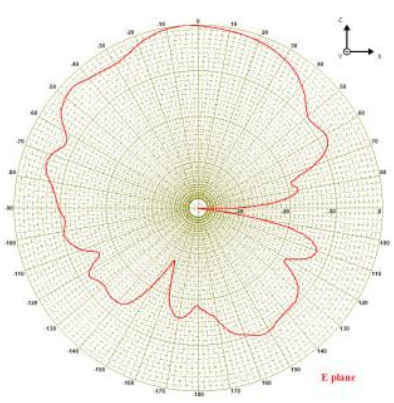

(b)

Figure 13. Measured radiation pattern at $0.915 \mathrm{GHz}(\mathrm{a})$ and $2.45 \mathrm{GHz}(\mathrm{b})$ in the E-plane

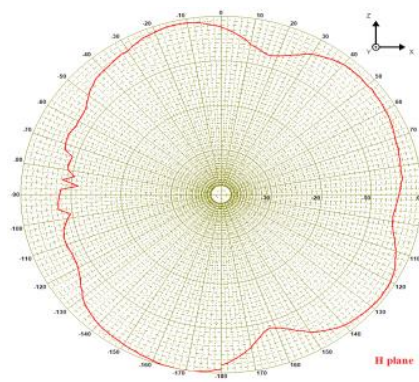

(a)

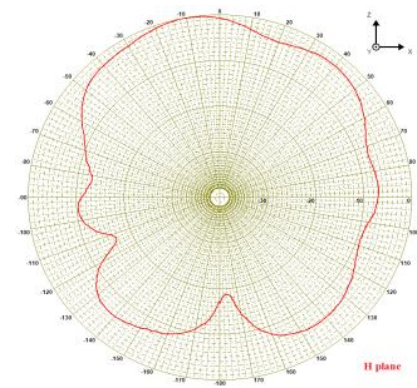

(b)

Figure 14. Measured radiation pattern at $0.915 \mathrm{GHz}(\mathrm{a})$ and $2.45 \mathrm{GHz}(\mathrm{b})$ in the $\mathrm{H}$-plane

To highlight the interesting performances of the designed antenna in term of size, resonance frequency and gain, we have conducted a comparative study of our propsed antenna with similar antennas presented in bibliography and the results are reported in the Table 2. It is clear from this table that the proposed work exhibits good features appropriate for dual-band RFID applications.

Table 2. The Designed Antenna Performances Compared with Other Antennas in Literature

\begin{tabular}{ccccc}
\hline Published literature & $\begin{array}{c}\text { Antenna Size } \\
\text { versus proposed work }\end{array}$ & $\left(\mathrm{mm}^{2}\right)$ & $\begin{array}{c}\text { Resonance frequency } \\
(\mathrm{GHz})\end{array}$ & \multicolumn{2}{c}{ Return loss $(\mathrm{dB})$} \\
\hline Ref[15] & $71^{*} 94$ & $0.915 / 2.45 / 5.8$ & -11 & $\mathrm{~F}_{1}$ \\
Ref[16] & $30^{*} 59.5$ & $0.868 / 2.5$ & -16.24 & -19.7 \\
Ref[21] & $76^{*} 35$ & $0.867 / 2.45$ & -13.05 & -14.37 \\
Proposed work & $48^{*} 47$ & $0.915 / 2.45$ & -14.5 & -26.7 \\
\hline
\end{tabular}

\section{Conclusion}

In this paper, we proposed a new dual-band and miniature microstrip antenna for RFID reader based on the slot technique. The differents steps for optimizing the antenna were carried out using CST Microwave Studio solver and ADS. The simulated and experimental results are in good agreement. The structure is validated in two frequency bands $(900-928 \mathrm{MHz})$ and $(2.4-$ $2.5 \mathrm{GHz}$ ), which cover the RFID Operating Frequency at UHF and Microwave RFID bands. The proposed structure exhibit good performances in terms of compactness and ease of fabrication which makes it very attractive for wireless applications especially for current RFID applications. 


\section{Acknowledgment}

We are thankful to the Professor Mr. Mohamed LATRACH from the Engineering Institute of electronic ESEO in Angers, France for permitting us to use and to perform simulations by using softwares and measurement on the VNA and anechoic chamber.

\section{References}

[1] K Finkenzeller. RFID Handbook: Fundamentals and Applications in Contactless Smart Cards and Identification, 3rd Edition. John Wiley and Sons Inc. New York. 2010.

[2] D Brown. RFID Implementation. Inc. New York. McGraw-Hill. 2007.

[3] Daniel MD. The RF in RFID Passive UHF RFID in Practice. Elsevier Inc. 2008.

[4] A ElHamraoui, El Abdelmounim, J Zbitou, H Bennis, M Latrach. Compact dual-band microstrip slot antenna for UHF and microwave RFID applications. Oral, 11th IEEE International Conference on Intelligent Systems: Theories and Applications (SITA) Conference. Mohammadia, Morocco. 2016.

[5] P Foster, R Bueberry. Antenna problems in RFID systems. IEE Coll. on RFID Technology. 1999; 3/1$3 / 5$.

[6] I Ismail, SM Norzeli. UHF RFID Reader Antenna with High Gain. International Journal of Electrical \& Electronic Systems Research (IEESR).

[7] SM Abbas, B Aftab, E Qamar, F Muzahir, S Shahid, H Zahra. High Gain Broadband Monopole Antenna for Wireless Communications. IEEE Antennas and Propagation Letters. 2012; 156.

[8] Yanzhong Y, Yanfei L, Jingxuan N. Miniaturized Design of a CP Antenna for UHF RFID Reader. International Journal of Electronics \& Communication (IIJEC). 2015.

[9] R Cao, SC Yu. Wideband Compact CPW-Fed Circularly Polarized Antenna for Universal UHF RFID Reader. IEEE Transactions on Antennas and Propagation. 2015; 63.

[10] ZN Chen, Q Xianming, HL Chung. A universal UHF RFID reader antenna. IEEE Transactions on Microwave Theory and Techniques.

[11] A Ennajih, J Zbitou, M Latrach, A Errkik, LE Abdellaoui, A Tajmouati. Dual Band Metamaterial Printed Antenna Based on CSRR for RFID Applications. International Journal of Microwave and Optical Technology. 2017; 12(2).

[12] T Shanmuganantham, S Raghavan. Design of Compact Coplanar Waveguide Fed Slot Antenna for RFID Applications. International Journal of Microwave and Optical Technology. 209; 4(1).

[13] H Tizyi, F Riouch, A Najid, A Tribak, A Mediavilla. Design of a Compact Dual-band Microstrip RFID Reader Antenna. International Journal of Microwave and Optical Technology. 2016; 11(2).

[14] A Ghiotto, A Ibrahiem, TP Vuong, S Tedjini. New Bi-Band Fractal Antennas. Oral, 12th IEEE International Symposium on Antenna Technology and Applied Electromagnetics [ANTEM] and the Canadian Radio Sciences (CNC-URSI) [URSI] Conference. Montréal, Canada. 2006.

[15] M Ihamji, E Abdelmounim, H Bennis, M Hefnawi, M Latrach. Design of Compact Tri-Band Fractal Antenna for RFID Readers. International Journal of Electrical and Computer Engineering (IJECE). 2017; 7(4): 2036-2044.

[16] KKA John, J Abraham, T Mathew. Dual Band Dipole Antenna for RFID/WSN Applications. Intenational Conference on Electronics and Communication System ICECS. 2014.

[17] Parvathy AR, Thomas KM. Reduction in Size Of The Microstrip Patch Antenna For Rfid Frequencies Using Fractals. International Journal PISER 13. 2013; 02(03/06).

[18] A Balanis. Antenna Theory Analysis and Design, 2nd edition. John Wiley \& Sons Inc. 2003.

[19] CST Studio Suite version 2010: http://www.cst.com/Content/Products/DS/Overview.aspx.

[20] Advanced Design System (ADS): http://www.home.agilent.com/agilent/home.js

[21] R Karli, H Ammor. A Simple and Original Design of Multi-Band Microstrip Patch Antenna for Wireless Communication. International Journal of Microwaves Applications. 2013; 2(2). 